\title{
Recall and organization in memory as a function of rate of presentation and individual differences in test anxiety
}

\author{
JOHN H. MUELLER, MICHAEL CARLOMUSTO, and MATTHEW MARLER \\ University of Missouri, Columbia, Missouri 65201
}

\begin{abstract}
Subjects differing in test anxiety participated in a free recall experiment using a list of words that could be organized by associates or rhymes. The words were presented at either a 1-sec or a 6-sec rate, with related words presented consecutively in input. Compared to low-anxiety subjects, high-anxiety subjects recalled fewer rhyming words and had fewer rhyme clusters, but there was no difference for recall of associates or associative clustering. High anxiety seemed to be more debilitating for women than for men. The results suggest an interpretation of the high-anxiety cue-utilization deficit in terms of the distinction between "elaborative" and "maintenance" rehearsal.
\end{abstract}

Subjects with high test-anxiety scores typically recall fewer words and show less organized free recall than lowanxiety subjects (Mueller, 1978). This deficit may be viewed in terms of reduced cue utilization (Easterbrook, 1959; Kausler \& Trapp, 1960), in that word features that might help organize the list are not encoded or not employed during retrieval (Eysenck, 1977; Mueller, 1976).

The primary purpose of this experiment was to determine the effect of rate of presentation on this deficit. Rate of presentation is of interest for several reasons, but especially in terms of its implications for an extension of the depth-of-processing analysis (Craik \& Lockhart, 1972) to the anxiety deficit (Mueller, 1976). It has been hypothesized (Eysenck, 1977) that arousal biases the subject's attention toward readily accessible features. While semantic content would normally be dominant with meaningful words, time pressure could lead to focusing on usually nondominant (physical) features. Mueller (1976) and Schwartz (1975) have argued that high arousal and anxiety involve relatively less processing of semantic content than information about physical features, compared to low arousal or anxiety. Since deep semantic features seem to require more time for encoding than shailow attributes (Craik \& Tulving, 1975), it may be that this time differential is greater for high- than for low-anxiety subjects. This leads to the prediction that the anxiety deficit would be reduced with slow presentation rates, and the improvement should be most apparent for semantic content. While even the fast rate used here would normally seem sufficient for semantic encoding, there may still be

Requests for reprints should be sent to John H. Mueller, Psychology Department, 210 McAlester Hall, University of Missouri, Columbia, Missouri 65201. This research was supported in part by funds from the Graduate School Research Council of the University of Missouri. The authors wish to acknowledge the contributions of Donald Kausler. differences in the utilization of study time and how it is allocated to rehearsal and attributes at different levels.

The present experiment used a multiclassifiable free recall task to examine this question (cf. Mueller, 1978). The words could be grouped into triads involving a base word, an associate, and a rhyme (e.g., BREAD, THREAD, NEEDLE), providing a contrast of deep and shallow encodings. The word list was the same as that used by Mueller, Carlomusto, and Marler (1977), and other procedures were also similar, except that control of exposure duration required single-item presentation rather than whole-list display.

\section{METHOD}

\section{Subjects and Design}

Subjects were selected from a large pool of introductory psychology students who had previously taken Sarason's (1972) Test-Anxiety Scale. Written informed consent was obtained prior to the experiment. High-anxiety subjects had test-anxiety scores greater than 27 , and low-anxiety subjects had scores below 9. The scores were comparable for high-anxiety males and females (means $=30.1$ and 32.0 , respectively) and for lowanxiety males and females (means $=5.1$ and 6.9 ). The experimental design was a 2 by 2 by 2 factorial, for test anxiety, rate of presentation, and sex.

\section{Materials}

The word list was composed of 12 triads, each consisting of a base word (e.g., CHAIR), its primary associate (e.g., TABLE) in the Shapiro and Palermo (1968) atlas, and a rhyme (e.g., SHARE). Two different versions of the list were utilized.

The items were presented one at a time, with triad members blocked consecutively in input. For half the triads on a trial, the order was associate, base, rhyme and rhyme, base, associate for the others, with the two orders mixed within a trial. Four different presentation orders were utilized over trials, with specific triads appearing in both the first and second half of a trial equally often, and each appearing twice in the associatebase-rhyme order and twice in the reverse order. Subjects were not informed of the blocking arrangement, nor the presence of the relationships. 


\section{Procedure}

Subjects had four trials on the list, with the 36 words presented at either a $1-\sec$ or a 6 -sec rate by slide projector followed by an immediate $90-\mathrm{sec}$ written test each time. Instructions emphasized the option to recall the words in any order, and to write them down as rapidly as possible. The experimenter said "mark" after $45 \mathrm{sec}$ of each test had elapsed, at which signal subjects drew a line under their last word recalled at that point and continued writing.

There was a delay of about 5 min after the fourth test, involving digit-span tests from the WAIS and a questionnaire. This was followed by an unannounced 90 -sec written test without further study. Finally, the subjects were contacted by telephone a week (6-8 days) later for an unannounced 90 -sec oral recall test.

At the beginning of the experiment, and again after the digit-span test, subjects completed the 20-item State Anxiety Inventory (Spielberger, Gorsuch, \& Lushene, 1970) and the short form of the Thayer Activation-Deactivation Adjective checklist (Thayer, 1967), counterbalancing usage as first and second tasks. Subjects selected for their high and low scores on the Test-Anxiety Scale also differed significantly $(p<.0001)$ on the State Anxiety Inventory (means $=47.6$ and 33.9, SDs $=10.06$ and 8.49 , respectively). However, none of the Thayer subscale differences was statistically significant (ps > .05). Finally, at the end of the experiment, subjects were asked to rate their anxiety during the experiment, and high test-anxious subjects assigned significantly higher ratings $(\mathrm{p}<.0001)$. To assure differential situational anxiety, the instructions indicated that the experiment concerned the relationship between intelligence, recall, and the screening inventory. Experimental debriefing thoroughly explained this and other aspects of the study.

\section{RESULTS $^{1}$}

\section{Immediate Tests}

Recall. Table 1 summarizes performance for Trials 1-4 over the entire test period. The slow rate of presentation led to more recall of associates, base words, and rhymes $(\mathrm{F}=17.93,11.78,13.13 ; \mathrm{MSe}=7.34$, $6.26,8.46$, respectively). The finding that rhyme and associate recall differed more at slower rates seems to replicate the findings of Folarin (1976), although in the latter study exposure duration was actually held constant. (However, a different pattern emerged for delayed recall here.)

High anxiety led to less rhyme recall $(F=6.66)$, but there was no difference for associate and base word recall $(\mathrm{Fs}<1)$. The Anxiety by Rate interaction was not significant for any of the three word types (Fs < 1.54).

The Anxiety by Sex interaction was significant for rhyme recall $(\mathrm{F}=4.34)$, as high anxiety had little effect on the performance of males but hindered the performance of females (means $=5.98,6.19,5.92$, and 7.88 , for high- and low-anxiety males and high- and lowanxiety females, respectively). This interaction was also present for the base words $(F=4.43)$; in this case, high anxiety improved the performance of males but hindered the performance of females (means $=8.42$, $7.56,7.79$, and 8.46). The latter trend was also present for associate recall, but it was not significant $(F=2.82)$. No other main effects or interactions were significant.
Table 1

Average Recall, Clusters, and Triad Recall per Trial on Trials 1-4, by Test Anxiety and Presentation Rate, for the Entire Test (ET) and the First Half of the Test (FH)

\begin{tabular}{|c|c|c|c|c|c|c|c|c|}
\hline & \multicolumn{4}{|c|}{ High Anxiety } & \multicolumn{4}{|c|}{ Low Anxiety } \\
\hline & \multicolumn{2}{|c|}{$1 \mathrm{Sec}$} & \multicolumn{2}{|c|}{$6 \mathrm{Sec}$} & \multicolumn{2}{|c|}{$1 \mathrm{Sec}$} & \multicolumn{2}{|c|}{$6 \mathrm{Sec}$} \\
\hline & ET & FH & ET & $\mathrm{FH}$ & ET & FH & ET & $\mathrm{FH}$ \\
\hline & \multicolumn{8}{|c|}{ Recall } \\
\hline $\begin{array}{l}\text { Associate } \\
\text { Rhyme } \\
\text { Base Word }\end{array}$ & $\begin{array}{l}6.92 \\
5.44 \\
7.71\end{array}$ & $\begin{array}{l}5.54 \\
4.31 \\
6.15\end{array}$ & $\begin{array}{l}8.65 \\
6.46 \\
8.50\end{array}$ & $\begin{array}{l}6.42 \\
4.67 \\
6.50\end{array}$ & $\begin{array}{l}6.02 \\
6.94 \\
7.17\end{array}$ & $\begin{array}{l}5.46 \\
4.58 \\
5.65\end{array}$ & $\begin{array}{l}8.52 \\
8.04 \\
8.86\end{array}$ & $\begin{array}{l}6.17 \\
6.73 \\
6.97\end{array}$ \\
\hline $\begin{array}{l}\text { Associate } \\
\text { Rhyme }\end{array}$ & $\begin{array}{l}5.29 \\
3.29\end{array}$ & $\begin{array}{l}4.15 \\
2.71\end{array}$ & $\begin{array}{l}6.94 \\
3.15\end{array}$ & $\begin{array}{l}\text { Clus } \\
5.17 \\
2.54\end{array}$ & $\begin{array}{l}\text { sters } \\
5.75 \\
3.10\end{array}$ & $\begin{array}{l}4.52 \\
2.54\end{array}$ & $\begin{array}{l}6.69 \\
5.27\end{array}$ & $\begin{array}{l}5.29 \\
4.13\end{array}$ \\
\hline $\begin{array}{l}\text { Represented } \\
\text { Consecutive } \\
\text { Anywhere }\end{array}$ & $\begin{array}{r}9.50 \\
.32 \\
.45\end{array}$ & $\begin{array}{r}7.40 \\
.34 \\
.47\end{array}$ & $\begin{array}{r}10.58 \\
.37 \\
.58\end{array}$ & $\begin{array}{l}\text { Tria } \\
7.67 \\
.39 \\
.61\end{array}$ & $\begin{array}{l}\text { ads } \\
9.13 \\
.42 \\
.60\end{array}$ & $\begin{array}{r}6.90 \\
.42 \\
.60\end{array}$ & $\begin{array}{r}10.81 \\
.49 \\
.72\end{array}$ & $\begin{array}{r}8.19 \\
.49 \\
.74\end{array}$ \\
\hline & \multicolumn{8}{|c|}{ Errors } \\
\hline Proportion & .05 & .04 & .04 & .03 & .10 & .06 & .02 & .01 \\
\hline
\end{tabular}

Clustering. Slower presentation led to more clustering of both rhymes and associates ( $F s=5.15$ and 10.43 ; MSe $=9.52$ and 7.68). This apparently contradicts Folarin (1976), perhaps due to methodological differences such as exposure duration and different definitions of semantic and acoustic similarity.

High anxiety led to less rhyme clustering $(\mathrm{F}=4.73)$, but high- and low-anxiety subjects were comparable for associative clustering $(\mathrm{F}<1)$. There was an Anxiety by Rate interaction for rhyme clustering $(F=6.74)$, as low-anxiety subjects showed more rhyme clustering than high-anxiety subjects with slower presentation, with little difference at fast rates. There was an Anxiety by Sex interaction for associative clustering $(F=9.13)$, as low-anxiety females showed more clustering than high-anxiety females but low-anxiety males showed less clustering than high-anxiety males (means $=6.67,5.56$, 5.56 , and 6.88 , for high- and low-anxiety males and high- and low-anxiety females, respectively). No other effects were significant.

Triad recall. The tendency to recall entire triads in output, with members either consecutive or anywhere in output, provides another index of organization. The number of whole triads recalled was divided by the number of base words recalled, since access to the base words could be considered an opportunity to recall the other two members. ${ }^{2}$

High-anxiety subjects showed less triad recall by the lenient (anywhere) criterion $(\mathrm{F}=8.15, \mathrm{MSe}=.12)$, but this effect was only marginal for the strict (consecutive) scoring $(\mathrm{F}=3.49$, MSe $=.17, \mathrm{p}<.07)$. This pattern of results suggests that high-anxiety subjects may be less likely to reinspect their output protocols during the later stages of a test, or less likely to benefit from it. Slower presentation rates led to more triad recall only for the lenient criterion $(F=6.85)$. 
The number of triads represented in recall by at least one member was also considered. This analysis revealed no anxiety effect $(F<1)$, but slower presentation did lead to more triads represented $(\mathrm{F}=16.68, \mathrm{MSe}=6.65)$.

Errors. The number of errors (duplications plus intrusions) for each subject was divided by the total number of responses made (correct and incorrect) to provide a measure of what proportion of the subject's performance was in error; presumably, a higher proportion would correspond to a lower degree of caution. The anxiety main effect was not significant $(F<1)$, but slower rates of presentation led to lower error rates $(\mathrm{F}=8.23, \mathrm{MSe}=.01)$, and there was an Anxiety by Rate interaction $(F=6.19)$, with low-anxiety subjects showing a higher error rate than high-anxiety subjects with fast presentation but not with the slow rate.

Early output. The split-test procedure was used in an attempt to assess anxiety differences in rate of-recall. The means are presented in Table 1; since the "firsthalf" recall comprised the bulk of total performance, virtually the same effects as reported above were significant, so they will not be presented here. The proportion of all recall that occurred during the first half of the test was approximately $.75-.80$ for all word types, and very similar for high- and low-anxiety subjects. The only evidence of an anxiety difference was that $65.5 \%$ of all errors by high-anxiety subjects occurred in the first half, compared to $57.8 \%$ for low-anxiety subjects.

Digit span. The forward digit spans were 7.2 and 7.4 for high- and low-anxiety subjects, respectively, while the backward spans were 5.9 and 6.8 . This difference was significant for the backward span $(F=4.32$, MSe $=2.13$ ), but not for the forward span or the combined scores $(\mathrm{Fs}<1)$. Over all subjects, total digit span was not correlated with recall of any of the word types, clusters, or triad recall (ps > .12), nor were any of these correlated significantly with the forward or backward spans.

\section{First Delayed Test}

Recall. Table 2 summarizes performance on both of the delayed tests. These data are of interest because of the possibility that anxiety effects might differ for long vs. short retention intervals in the manner that has been predicted by the action-decrement hypothesis in arousal research (cf. Eysenck, 1977). The analogous long-term superiority of high anxiety did not develop here, a failure that seems typical in free recall research (Eysenck, 1977, p. 166). Most of the present measures merely showed the attenuation or the carryover of acquisition differences. From the depth perspective, shallow traces decay, so depth-of-encoding effects should be more pronounced on a delayed test. Yet, if anything, associates may have shown a slightly greater loss than rhymes here.

The slow rate led to superior recall of rhymes, associates, and base words $(\mathrm{Fs}=8.14,15.13$, and 11.29;
Table 2

Average Recall, Clusters, and Triad Recall on the Delayed Tests, by Test Anxiety and Presentation Rate

\begin{tabular}{|c|c|c|c|c|c|c|c|c|}
\hline & \multicolumn{4}{|c|}{ High Anxiety } & \multicolumn{4}{|c|}{ Low Anxiety } \\
\hline & \multicolumn{2}{|c|}{$1 \mathrm{Sec}$} & \multicolumn{2}{|c|}{$6 \mathrm{Sec}$} & \multicolumn{2}{|c|}{$1 \mathrm{Sec}$} & \multicolumn{2}{|c|}{$6 \mathrm{Sec}$} \\
\hline & D1 & D2 & D1 & D2 & D1 & D2 & D1 & D2 \\
\hline & \multicolumn{8}{|c|}{ Recall } \\
\hline $\begin{array}{l}\text { Associate } \\
\text { Rhyme } \\
\text { Base Word }\end{array}$ & $\begin{array}{l}7.75 \\
6.75 \\
8.67\end{array}$ & $\begin{array}{l}5.58 \\
3.25 \\
5.92\end{array}$ & $\begin{array}{l}9.50 \\
7.92 \\
9.42\end{array}$ & $\begin{array}{l}6.92 \\
4.17 \\
7.17\end{array}$ & $\begin{array}{l}8.00 \\
7.00 \\
8.17\end{array}$ & $\begin{array}{l}4.67 \\
3.50 \\
5.17\end{array}$ & $\begin{array}{r}10.00 \\
9.75 \\
10.25\end{array}$ & $\begin{array}{l}6.92 \\
5.75 \\
7.42\end{array}$ \\
\hline Base Word & \multicolumn{8}{|c|}{ Clusters } \\
\hline Rhymes & $\begin{array}{l}6.08 \\
4.42\end{array}$ & $\begin{array}{l}4.50 \\
1.83\end{array}$ & $\begin{array}{l}7.08 \\
4.17\end{array}$ & $\begin{array}{l}5.67 \\
1.33\end{array}$ & $\begin{array}{l}6.17 \\
3.58\end{array}$ & $\begin{array}{l}3.42 \\
2.17\end{array}$ & $\begin{array}{l}8.50 \\
6.83\end{array}$ & $\begin{array}{l}5.50 \\
4.25\end{array}$ \\
\hline $\begin{array}{l}\text { Represented } \\
\text { Consecutive } \\
\text { Anywhere }\end{array}$ & $\begin{array}{r}10.42 \\
.43 \\
.61\end{array}$ & $\begin{array}{r}7.25 \\
.32 \\
.41\end{array}$ & $\begin{array}{r}11.50 \\
.45 \\
.74\end{array}$ & $\begin{array}{r}\text { Tri } \\
9.50 \\
.18 \\
.34\end{array}$ & $\begin{array}{r}\text { ads } \\
10.50 \\
.48 \\
.68\end{array}$ & $\begin{array}{r}6.67 \\
.27 \\
.39\end{array}$ & $\begin{array}{r}12.25 \\
.68 \\
.87\end{array}$ & $\begin{array}{r}8.50 \\
.52 \\
.65\end{array}$ \\
\hline & \multicolumn{8}{|c|}{ Errors } \\
\hline Proportion & .04 & .07 & .04 & .06 & .05 & .19 & .02 & .02 \\
\hline
\end{tabular}

Note-D1 refers to means on the initial delayed test; $D 2$ refers to the corresponding values for the second delayed test after 1 week.

MSe $=5.65,2.79$, and 2.13 , respectively). The anxiety main effects were not significant and there were no Anxiety by Rate interactions (Fs $<2.50$ ). The proportion of all recall that occurred in the first half of the test was high, and comparable for high- and low-anxiety subjects (.72 vs. .74 , respectively.

Clustering. The only significant differences in the clustering data were more clustering with the slow rate for both rhymes and associates (Fs $=4.76$ and 7.66; $\mathrm{MSe}=5.68$ and 4.35, respectively), and an Anxiety by Rate interaction for rhyme clustering $(F=6.48)$.

Triad recall. The only significant difference for triad recall was a rate main effect for the lenient criterion $(\mathrm{F}=5.94$, MSe $=.05)$ and in the number of triads represented in recall $(\mathrm{F}=8.28, \mathrm{MSe}=2.91)$.

Errors. The error rate was higher for women than for men $(F=4.23, \mathrm{MSe}=.003)$, but no other effects were significant.

\section{Second Delayed Test}

Recall. The slow rate led to better recall of rhymes, associates, and base words after 1 week $(\mathrm{Fs}=10.23$, $11.90,10.11 ; \mathrm{MSe}=2.94,3.24,3.63$, respectively). High-anxiety subjects recalled a slightly greater number of rhymes $(F=3.43, p<.08)$, but there was no difference for associates and base words $(\mathrm{Fs}<1)$. There were no Anxiety by Rate interactions (Fs $<1.81$ ). The first half of the test period again produced high and comparable proportions of total recall for high-and low-anxiety subjects (.80 vs. .78 , respectively).

Clustering. Slower rates led to significantly more associative clustering $(\mathrm{F}=9.02, \mathrm{MSe}=3.51)$, but only marginally more rhyme clustering $(\mathrm{F}=3.75, \mathrm{MSe}=2.00$, $\mathrm{p}<.06$ ). Low-anxiety subjects had more rhyme clusters 
$(F=15.81)$, but not more associative clusters $(F=1.33)$. There was an Anxiety by Rate interaction for rhyme clustering $(F=9.99)$.

Triad recall. Low-anxiety subjects showed more triad recall for both the strict and lenient criterion $(F s=5.24$ and 4.56; MSe $=.05$ and .05 ), but the rate main effects were not significant $(\mathrm{Fs}<2.02)$. The Anxiety by Rate interaction was significant for both the strict and lenient scoring ( $F s=8.96$ and 5.81$)$; while both anxiety subgroups improved somewhat for the change from 1-sec to 6-sec presentation rates, the low-anxiety subjects showed the greater gain.

Errors. The error data revealed a marginal Anxiety by Rate interaction $(\mathrm{F}=3.90, \mathrm{MSe}=.02, \mathrm{p}<.06)$, and a significant rate main effect $(F=4.43)$. Fast presentation rate was associated with more errors, particularly for the low-anxiety subjects.

\section{DISCUSSION}

The present results provide further evidence for a highanxiety deficit in free recall performance, but there was no evidence that the deficit was limited to "semantic" content; in fact, the deficit was more apparent for "nonsemantic" attributes here, if anything. However, since the associative strength between the base word and associate was not equated with that between the base word and rhyme, an alternative conclusion might be that the deficit involves primarily weak relationships. Of course, a direct comparison of associative strength within the same attribute level would be required to establish this for certain. In spite of the confounding of attribute depth and associative strength, the results suggest an interpretation based more on type of rehearsal than type of attribute processed. Actually, the rehearsal analysis is strengthened if the rhymeassociate manipulation is viewed as a weak-strong associative dimension rather than the intended shallow-deep difference. The argument can be briefly summarized as follows.

Generally, high-anxiety subjects utilized extra time about as well as low-anxiety subjects, except in the case of rhyme clusters. The latter result seems at variance with the idea that it is deep features that require more time for processing. This suggests that weak or peripheral relationships (e.g., rhymes) are not utilized by high-anxiety subjects, and that they do not utilize memorial strategies as complex as those of lowanxiety subjects (e.g., triad recall). Since high-anxiety subjects did not recall more rhyme clusters or whole triads even when given more time, this indirectly suggests they may be more prone to "maintenance" rehearsal. Subjects who are encoding "elaboratively," such as low-anxiety subjects, may benefit from the slower rate by using the additional time to incorporate peripheral attributes. Further evidence is required, but this distinction may be of more value in future anxiety-memory research than the simple dichotomy between semanticnonsemantic processing, although the latter may still be a factor. work for memory research. Journal of Verbal Learning and Verbal Behavior, 1972, 11, 671-684.

Craik, F. I. M., \& Tulving, E. Depth of processing and the retention of words in episodic memory. Journal of Experimental Psychology: General, 1975, 1, 268-294.

EASTERBROOK, J. A. The effect of emotion on cue utilization and the organization of behavior. Psychological Review, 1959, 66, 183-201.

EYSENCK, M. W. Human memory: Theory, research and individual differences. Oxford: Pergamon Press, 1977.

FolARIN, B. A. The effect of presentation rate on categorization. British Journal of Psychology, 1976, 28, 27-33.

KAusler, D. H., \& TrAPp, E. P. Motivation and cue utilization in intentional and incidental learning. Psychological Review, 1960, 67, 373-379.

Mueller, J. H. Anxiety and cue utilization in human learning and memory. In M. Zuckerman \& C. D. Spielberger (Eds.), Emotions and anxiety: New concepts, methods and applications. Hillsdale, N.J: Lawrence Erlbaum, 1976.

Mueller, J. H. The effects of individual differences in test anxiety and type of orienting task on levels of organization in free recall. Journal of Research in Personality, 1978, 12, 100-116.

Mueller, J. H., Carlomusto, M., \& Marler, M. Recall as a function of method of presentation and individual differences in test anxiety. Bulletin of the Psychonomic Society, 1977, 10, 447-450.

SARASON, I. G. Experimental approaches to test anxiety: Attention and the uses of information. In C. D. Spielberger (Ed.), Anxiety: Current trends in theory and research (Vol. 2). New York: Academic Press, 1972.

SCHWARTZ, S. Individual differences in cognition: Some relationships between personality and memory. Journal of Research in Personality, 1975, 9, 217-225.

Shapiro, S. I., \& Palermo, D. S. An atlas of normative free association data. Psychonomic Monograph Supplements, 1968, 2, No. 12(Whole No. 28).

SPielberger, C. D., Gorsuch, R. L., \& Lushene, R. E. Manual for the state-trait anxiety inventory. Palo Alto, Calif: Consulting Psychologists Press, 1970.

THAYER, R. E. Measurement of activation through self-report. Psychological Reports, 1967, 20, 663-678.

\section{NOTES}

1. Effects described as significant involve $p<.05$, unless noted otherwise. All Fs involved 1 and 40 degrees of freedom. All analyses of immediate recall performance included trials as a repeated-measures factor. However, trials entered into no interactions, and the persistent main effect of trials merely indicated the occurrence of acquisition, so these effects will not be reported.

2. Another analysis involved dividing total recall by 3 , to get the maximum number of triads possible, and dividing that into the number of whole triads recalled. This yielded the same statistical conclusions.

\section{REFERENCES}

